\title{
T1 Translational Research
}

National Cancer Institute

\section{Source}

National Cancer Institute. T1 Translational Research. NCI Thesaurus. Code C84346.

The transfer of new understandings of disease mechanisms gained in the laboratory into the development of new methods for diagnosis, therapy, and prevention including their testing in humans and the use of observations made during clinical research to identify new avenues of research for the laboratory. 